\title{
AFGHANISTAN
}

PROJECT FINDINGS AND RECOMMENDATIONS

UNITED NATIONS DEVELOPMENT PROGRAMME

FOODAND AGRICULTURE ORGANIZATION OF THE UNITED NATIONS ROME, 1995 


\section{SUPPORT TO VETERINARY CLINICS}

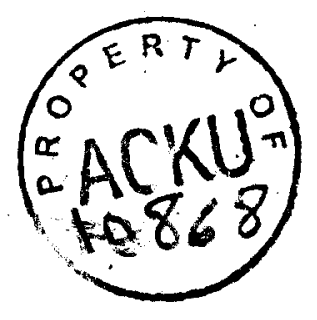

\section{AFGHANISTAN}

\section{PROJECT FINDINGS AND RECOMMENDATIONS}

Report prepared for the Government of Afghanistan by the Food and Agriculture Organization of the United Nations acting as executing agency for the United Nations Development Programme 
The designations employed and the presentation of the material in this document and map do not imply the expression of any opinion whatsoever on the part of the United Nations or the Food and Agriculture Organization of the United Nations concerning the legal status of any country, territory, city or area or of its authorities, or concerning the delimitation of its frontiers or boundaries. 
The Food and Agriculture Organization is greatly indebted to all those who assisted in the implementation of the project by providing information, advice and facilities. 
IV 


\section{TABLE OF CONTENTS}

$\underline{\text { Page }}$

LIST OF ABBREVIATIONS vi vi

1. INTRODUCTION 1

1.1 Project background 1

1.2 Outline of official arrangements 2

$\begin{array}{ll}1.3 \text { Objectives of the project } & 2\end{array}$

$\begin{array}{lll}1.4 & \text { Project implementation and constraints } & 3\end{array}$

$\begin{array}{ll}1.5 & \text { Project reformulation }\end{array}$

2. RESULTS AND CONCLUSIONS 5

$\begin{array}{ll}2.1 & \text { Rehabilitation of clinics }\end{array}$

2.1.1 Renovation of clinics and assistance to dispensaries 6

$\begin{array}{lll}2.1 .2 & \text { Provision of cold storage equipment } & 7\end{array}$

2.1.3 Provision of veterinary supplies and equipment 8

$\begin{array}{lll}2.2 & \text { Training } & 12\end{array}$

$\begin{array}{lll}2.3 & \text { Disease control programme } & 13\end{array}$

$\begin{array}{ll}2.4 & \text { Livestock data collection } \\ 2.5 & 15\end{array}$

2.5 Commercial supply of veterinary needs $\quad 15$

$\begin{array}{lll}2.6 & \text { Future development } & 16\end{array}$

$\begin{array}{ll}3 . & \text { RECOMMENDATIONS } \\ \end{array}$

$\begin{array}{lll}3.1 & \text { Legalizing veterinary private practice } & 17\end{array}$

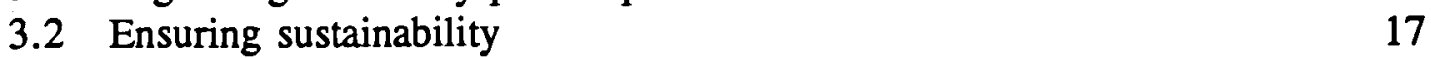

$\begin{array}{ll}3.3 \text { Veterinary public health } & 18\end{array}$

$\begin{array}{ll}3.4 & \text { Privatization of veterinary medicine distribution } \\ \end{array}$

$\begin{array}{lll}\text { Appendix 1 PROJECT STAFF } & 21\end{array}$

$\begin{array}{lll}\text { Appendix } 2 & \text { STUDY TOURS }\end{array}$

Appendix 3 MAJOR ITEMS OF EQUIPMENT PROVIDED 23

Appendix 4 DOCUMENTS PREPARED DURING THE PROJECT 25

Appendix 5 MAP OF PROJECT AREA IN AFGHANISTAN 27

\section{LIST OF TABLES}

1. Animals treated by the project (January 1993 to January 1994) 9

2. Vaccinations reported (all species combined) 14 


\section{LIST OF ABBREVIATIONS}

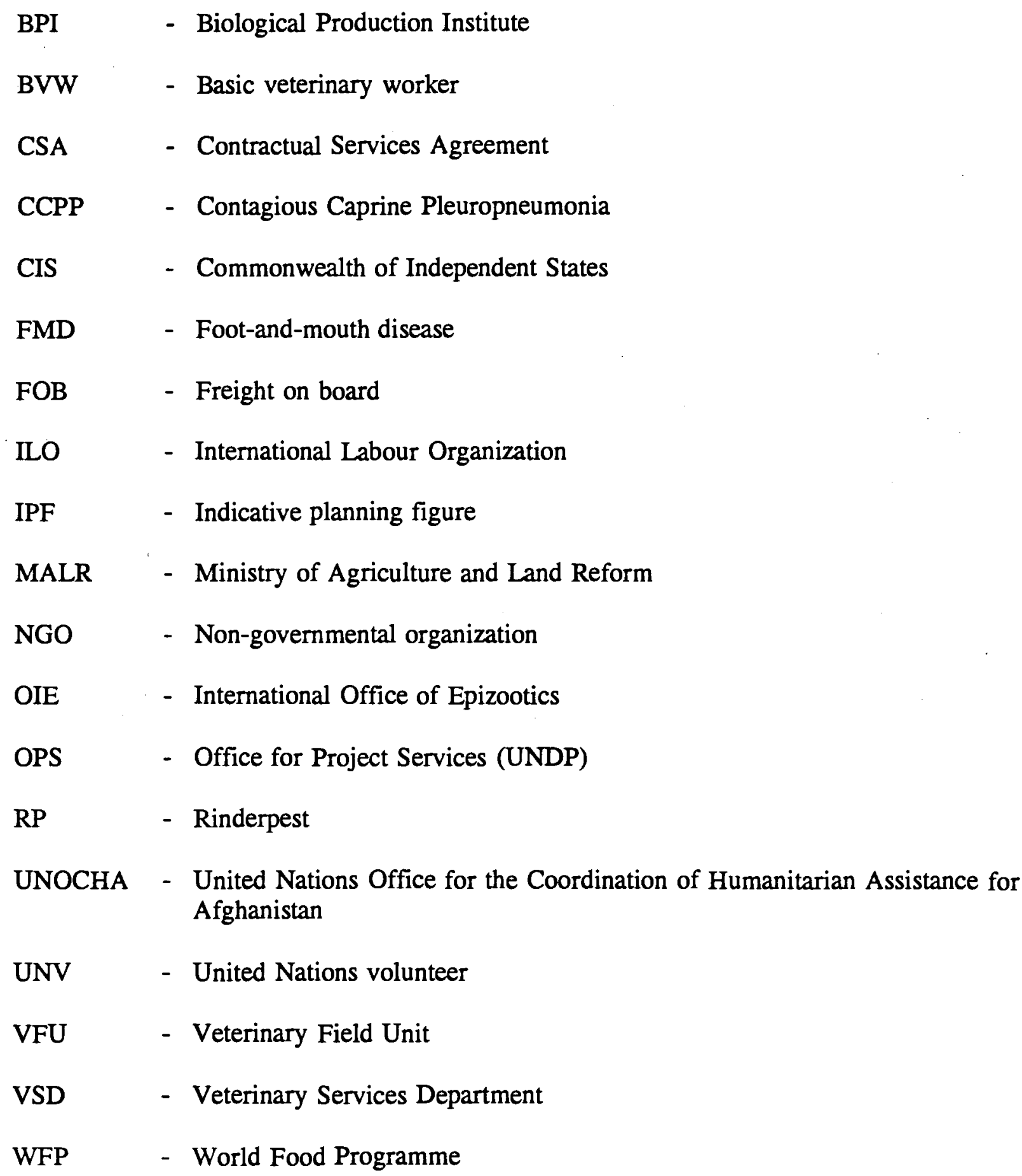




\section{INTRODUCTION}

\subsection{PROJECT BACKGROUND}

Over $80 \%$ of the population of Afghanistan is engaged in agriculture. Throughout the years of war, livestock was crucial to the survival of rural families. Before 1988 the livestock subsector was responsible for up to $40 \%$ of the total export earnings. Years of devastation have had serious consequences on the animal population, yet the livestock subsector has the potential of rebuilding itself more rapidly than other sectors.

The Government decided in 1989 to initiate priority programmes to preserve the remaining herds and flocks in the country and to restore livestock numbers and productivity to at least pre-war levels. It was envisaged that this could be achieved through an improved animal health service which would reduce mortality in all species by $50 \%$ or more when vaccines and remedies were made available on a regular basis. Government statistics for 1991 estimated the livestock population in Afghanistan as follows (in millions): sheep: 14.0; goats: 3.3; cattle and buffalo: 2.9; horses, donkeys, mules and camels: 1.7; and poultry: 5.5 .

In past peaceful times, UNDP funds allocated to FAO were used to execute projects to establish a veterinary infrastructure, including the provision of assistance to the Veterinary Faculty and the Central Veterinary Institute as well as assistance in the production of animal vaccines.

In 1989, UNDP initiated the funding of a community-based cross-border programme for the south and southeast of Afghanistan, executed by the UNDP Office for Project Services (OPS). This assistance was of an emergency nature and focused on agricultural rehabilitation and animal health. Based in Pakistan, the OPS programme carried out its activities inside Afghanistan through various subcontracted non-governmental organizations (NGOs).

In view of the importance of the livestock population in the north and west of Afghanistan, the Government requested UNDP assistance in the implementation of a veterinary project in Mazar-i-Sharif with sub-offices in Herat, Kabul and Badakhshan and serving a total of 11 provinces. At the time of the signing of the Project Document, northern Afghanistan was relatively peaceful, as the battle fronts were further south and southeast. By basing the project inside the country and by working through national staff, without the intermediation of NGOs, a more direct implementation was pursued resulting in closer 
monitoring of project activities when compared with the OPS programme. Internal fighting broke out when the project was only nine months under way and, despite the fact that the project faced difficult circumstances for the rest of its duration, remarkable efforts were made and commendable results were achieved. These results can be attributed to the professionality of those involved and to the devotion and flexibility under stress of project staff during years of crisis.

\subsection{OUTLINE OF OFFICIAL ARRANGEMENTS}

The Project Document for project AFG/90/006 "Support to Veterinary Clinics" was signed by the Government, UNDP and FAO on 15 May 1991, with a scheduled duration of three years. FAO was designated as the executing agency, and the Ministry of Agriculture and Land Reform (MALR), Veterinary Services Department (VSD), as the government implementing agency. UNDP contribution, as finally adjusted, was \$US 2991085 , and that of the Government was Af 10059056 (in kind). Project activities were initiated on 5 July 1991 and completed on 30 September 1994.

\subsection{OBJECTIVES OF THE PROJECT}

One of the primary development goals of the Government was to increase agricultural productivity and production with a view to achieving food self-sufficiency and ensuring adequate living standards for all of the population. Given the situation in war-torn Afghanistan, the development objectives of the project were to assist in restoring livestock numbers and production to levels of a decade earlier, to increase livestock productivity, and to help rehabilitate the agriculture sector following the destruction and neglect of years of war.

The immediate objectives of the project were to:

- preserve remaining livestock and poultry through the implementation of disease control programmes in eight northern and western provinces of Afghanistan (Herat, Badghis, Jowzjan, Faryab, Balkh, Samangan, Kunduz and Badakhshan) as well as in Kabul province; and 
- - expand activities, if possible, into two other provinces (Takhar and Baghlan), and further coordinate animal health and production assistance in the country, provided that project experience indicated the feasibility of such an objective.

\subsection{PROJECT IMPLEMENTATION AND CONSTRAINTS}

A project office was established in Mazar-i-Sharif in August 1991. With the fall of the Negebulleh government and the subsequent outbreak of violence, international personnel were evacuated on 12 March 1992 from Mazar-i-Sharif to Kabul and from there to New Delhi, India, and Islamabad, Pakistan. They were allowed to return to Mazar-i-Sharif and Kabul in July 1992. A project sub-office was established in Herat in October 1992.

Security again became problematic in December 1992, resulting in the cancellation of consultancies and a backstopping mission. However, a project sub-office was established in Badakhshan in March 1993.

A national project veterinarian was assigned to Kabul in late 1993 and, despite the dangerous situation, was able to supply district veterinarians around Kabul with vaccines, medicines and instruments until May 1994, when his safety was at risk.

In early 1994, project activities were temporarily halted due to several days of violence in Mazar-i-Sharif, and international personnel were once again evacuated from Afghanistan. Local project personnel remained in Mazar-i-Sharif and kept a reduced staff operating at the main office during the January events. Project operations resumed routinely in early February 1994.

United Nations air travel to Termez in neighbouring Uzbekistan resumed toward the end of February, but the presence of international project personnel in Mazar-i-Sharif remained limited.

Security procedures requiring multiple clearances and travel in convoy with radioequipped vehicles were a time and budgetary constraint to project field trips. Nevertheless, their ultimate benefit was that during the civil war, loss of life was avoided and dangerous incidents kept to a minimum.

Despite the limitations imposed by fragile security and delayed logistics, project staff succeeded in carrying out activities in all project areas. 


\subsection{PROJECT REFORMULATION}

A Project Document was prepared for a project which would merge the northern FAO/UNDP project with the veterinary component of the southern OPS/UNDP programme into a countrywide Integrated Livestock Programme (AFG/93/004) under FAO execution. A review/formulation mission visited in March 1994 but, for security reasons, was unable to visit the project in the north. A Preparatory Assistance document was signed on 15 May 1994 with the starting date of the new programme set for 1 July 1994 . The Programme Manager for project AFG/93/004 arrived in Islamabad on 19 September 1994. 


\section{RESULTS AND CONCLUSIONS}

The project was conceived as an emergency measure for the preservation of existing livestock and poultry through the rehabilitation of veterinary clinics and the provision of disease control programmes in 11 provinces of northern Afghanistan. At the time the Project Document was signed, there existed a functional government veterinary service in the project area. With the collapse of the central government and the emergence of provincial or regional governments and non-government controlled areas, government veterinarians could no longer be paid by the Government. The promotion of the concept of a paying veterinary service, rather than the conventional free veterinary service previously provided by the Government, was based on the knowledge that farmers were willing and able to pay for veterinary services, medicines and vaccines which had long been lacking. Most of the government veterinarians in the project area were from Kabul province and they gradually established roots in rural areas after being based for many years in the same clinic while the rest of the country was at war. They were already making a modest income from private practice but lacked necessary medicines. To offer for sale and to recover the cost of those inputs was the project's solution toward fuller veterinary privatization. No salaries were paid by the project to government staff. It was in its insistence on full cost recovery and in the non-payment of salaries that the northern FAO project approach differed significantly from the southern OPS project. Government veterinarians considered themselves to be employed by the central Government even if they had not received any salary for a long time.

During the project period, a support system for community-based veterinary clinical services was established which contrasted with the previous veterinary service approach of offering treatment in clinics in major towns only. The innovation was the use of communitybased vaccinators (later called basic veterinary workers (BVWs), who served the outlying districts more extensively than had the government clinic. These BVWs were given the opportunity to make an income from their veterinary practice. Medicines were sold to BVWs who resold them at a $10 \%$ mark-up. Vaccines were supplied at no cost, but BVWs were allowed to charge a modest service fee. An attempt to also charge for the cost of vaccines had to be abandoned as important vaccine stocks would have remained unsold and left to expire. Legislation on costs charging policy has so far not been amended. 
The geographical area of the project expanded to 13 provinces with the addition of two other provinces (Bamyan and Sare Pul) to the original 11 foreseen in the Project Document. Takhar province was supported by the southern veterinary project where NGOs were active. The project covered most of the districts selected by UNDP for its community rehabilitation programmes, but activities also extended to districts in remote areas with large livestock populations where no United Nations operations existed. The project received support from the Veterinary Services Department in Kabul and in the provincial centres as well as from community leaders and local commanders. The project's sole reliance on international personnel was quickly redressed with the inclusion of national professionals within a year of project operation. The combination of both national and international project staff played a key role in negotiating acceptance from local leaders.

\subsection{REHABILITATION OF CLINICS}

One of the project objectives was to rehabilitate selected government clinics which were not functioning due to the breakdown in government zones. Rehabilitation consisted of the renovation of physical structures, the provision of start-up kits containing veterinary remedies and basic veterinary instruments, the equipping of clinics with cold storage equipment and vaccines and the provision of transport to field staff and clinics.

\subsubsection{Renovation of clinics and assistance to dispensaries}

Of the 20 government clinics identified (14 proper actual clinics and six dispensaries), 11 were renovated by the project. Renovations consisted of repairs to roofs, doors and windows, the provision of basic furniture and a cattle crush, and the construction of a well. The remaining clinics could not be considered due to security reasons. It was soon realized that these buildings were attractive to local troops, who occupied them as soon as renovations were completed. The buildings also fell prey to looting as rival Mujahedeen factions won or lost ground.

The priority of the project then shifted to assisting simple dispensaries. Some 57 dispensaries were established by private initiative and in some instances with community support, at the residence or rented building of the veterinarian or BVW. A total of 13 such dispensaries were established with the help of the project. Only materials not available 
locally were provided by the project. The total cost for all renovations amounted to approximately \$US 12000.

The modest rehabilitation of clinics in major centres contributed to the good working relationship between the provincial governments and the project. It was to the benefit of the project to recondition the laboratories and cold rooms for the purpose of disease investigation and to ensure proper vaccine storage. The subsequent assistance in establishing private dispensaries was better suited to the project's emphasis on privatization and had the additional benefit that private homes or shops were less likely to be looted or occupied by militia.

\subsubsection{Provision of cold storage equipment}

The main cold storage facility in Mazar-i-Sharif Veterinary Department, consisting of one above ground and one underground cold room, was repaired and a generator provided. It has a capacity of 7500000 doses of vaccine. Three new electric refrigerators and a generator were distributed to various districts and six existing ones repaired. Three solar refrigerators were installed and, at the time of writing, the delivery of the fourth was pending improvement of security. Quotations for kerosene refrigerators were obtained, but as funds were reduced they were not ordered. Twenty-five cold boxes and 22 vaccine carriers were distributed, and 750 recyclable vaccine transport boxes, originating from previous vaccine shipments, were stored in Mazar-i-Sharif to be used for transporting vaccine to the field. The total cost for cold storage equipment issued to clinics amounted to SUS 73657 .

Where electricity is available, an electric refrigerator or an air conditioner in an underground room with a stand-by generator are sufficient. Most power failures occur in winter when cold storage is not so critical. Temperatures between two to eight degrees Celsius are needed for such live types of vaccine as sheep pox and for imported vaccines, with the exception of the heat-resistant Newcastle disease vaccine for poultry. Solar refrigerators are easily installed and are maintenance-free. Although expensive at the time of purchasing, there are no subsequent running expenses involved. They are highly recommended for isolated places where there is no electricity or where kerosene is a scarce commodity.

With careful planning of the vaccination timing and vaccine ordering and distribution, vaccine losses from inadequate storage were kept to a minimum. 


\subsubsection{Provision of veterinary supplies and equipment}

The project distributed veterinary remedies and vaccines to clinics and dispensaries in 85 of the 99 districts in the project area including Kabul province. In the few cases that areas were inaccessible because of security reasons, veterinary workers went to the nearest project sub-office or main clinic to collect vaccine and purchase medicines. The project also supplied medicines and vaccines to two NGOs active in the project area upon their request.

\subsubsection{Medicines}

After issuing an initial free start-up supply of medicines and instruments to 20 clinics (kit value of \$US 563 each) and 62 dispensaries (kit value of \$US 304 each), the project embarked in late 1992 on a policy of full cost recovery without going through a phased introduction of cost recovery. Quality veterinary medicines were imported at a total cost of \$US 213131 and were sold to veterinary workers at freight-on-board (FOB) cost, calculated in afghanis at the original exchange rate prevailing at arrival of the medicines. The project recommended to the veterinarians and BVWs that they make a mark-up of approximately $10 \%$ to farmers, thus providing them with a source of income.

The illegal sale of Iranian-subsidized medicines in Herat province made project medicines more expensive. This market force was viewed positively as a step toward a commercial supply of medicines. Some medicines originating from NGOs active in the south were on sale in bazaars in the project area. Although these were cheaper, they were of a different and lower quality brand and generally not favoured by veterinary workers. Project medicines were also sold to two NGOs operating in the project area.

Supplies were made available by monitoring missions to remote areas and even to Kabul district clinics. In addition, veterinary workers travelled regularly to project offices to purchase medicines to replenish their supply. This motivation by the commercial aspect of the veterinary activities was viewed as a positive indicator of the project's impact as it reflected farmer demand.

The first issue of medicines was on credit, and re-issue of medicine was conditional to a repayment of $60 \%$ of the initial loan. The project stopped issuing medicines on credit as of mid-1993. Over the period 16 December 1992 to 30 June 1994, the project recovered a total of Af 56813441 from medicine sales. This amounts to \$US 34995 using various exchange rates as per imprest returns, but to \$US 47345 using the original exchange rate prevailing upon arrival of the medicines. By September 1994, the unrecovered credit for 
medicine sales amounted to Af 9554705 or \$US 7026 at the United Nations exchange rate for September. Thus the actual recovery rate was $83.3 \%$, which was an excellent result considering that the project terminated while this activity was well under way. The costrecovery aspect highlights another crucial difference between the OPS and FAO programmes in that the FAO project was not a hand-out emergency assistance but a rehabilitation programme.

Funds recovered from the sale of medicines were entered into the project imprest account. A proposal was made for the use of these funds for the procurement of further supplies through a Letter of Agreement with the Governor of Baghlan province, and through the establishment of a working committee to ensure the continuation of project activities on a self-sustaining basis, but due to the reformulation of the project into a new programme this arrangement was not pursued.

Due to the initially inaccurate and incomplete reporting from the national veterinary workers prior to 1993, it is difficult to estimate the number of animals which benefited from these medicines and vaccines. However, more reliable data from treatment reports of January 1993 to June 1994 show the extent of the project's impact for all species combined (cattle, sheep, goats, horses, donkeys, camels, dogs and poultry).

Table 1

ANIMALS TREATED BY THE PROJECT (January 1993 to June 1994)

\begin{tabular}{|c|c|}
\hline Treatment & No. of Animals \\
\hline $\begin{array}{l}\text { Clinical cases } \\
\text { Surgical cases } \\
\text { External parasites treatment } \\
\text { Internal parasites treatment } \\
\text { Castrations }\end{array}$ & $\begin{array}{r}214804 \\
11669 \\
668657 \\
476065 \\
39543\end{array}$ \\
\hline Total & 1410738 \\
\hline
\end{tabular}

An estimated 2000000 animals benefited from the medicines provided during the threeyear duration of the project, and additional numbers benefited from vaccination. Farmers came to realize that they could increase their profits considerably through improved livestock 
production with better young animals with diminished internal parasite burdens and with more hides and wool saved through a reduction of the external parasite load. Witness to this was an ever increasing demand by farmers for endo- and ecto-parasite remedies.

\subsubsection{Instruments}

The kit issued to veterinary workers of all categories who successfully graduated from the project's training course also contained a set of basic instruments. The value of the veterinarian's kit was \$US 304 and that of the BVW's kit was \$US 214. Better performing BVWs were later rewarded with additional instruments. The total cost of imported instruments amounted to \$US 92612 . Alternative manufacturers of instruments such as the Burdizzo castration pliers were identified in Pakistan, but their instruments were found to be of a lesser quality.

By providing both technical knowledge and essential tools, the project succeeded in creating up to 300 self-paying jobs.

\subsubsection{Vaccines}

With the destruction of the Biological Production Institute (BPI) in Kabul, vaccine was imported from overseas rather than from laboratories in Pakistan which had a limited production capacity. There were numerous calls from veterinary officials to rebuild the vaccine production plant, perhaps in a safer area such as Mazar-i-Sharif, but this seemed premature given the current unrest.

At a cost of \$US 514000 , a total of 13884700 doses of vaccines against different types of diseases (including 2200000 doses of Newcastle poultry vaccine, 1000000 doses of sheep pox, 9684700 doses of anthrax, haemorrhagic septicaemia, enterotoxaemia and blackleg and 300000 doses of contagious caprine pleuropneumonia) were imported and distributed. Assuming a normal wastage of $10 \%$ (or 1400000 doses) and an estimated $20 \%$ more ( 2500000 doses) stored in clinics beyond their expiry date, it can be concluded that some 10000000 animals were inoculated with optimally preserved vaccine. The actual number of vaccinations ( 7443 208) was below the estimated figure, which may lead to the conclusion that either a higher percentage of vaccine was wasted or was stored in clinics and dispensaries. 
These vaccinations reduced mortalities in various animal species and, as a result, such species as poultry and dairy cattle have improved the quality of human lives following years of malnutrition.

\subsubsection{Transport equipment}

Three clinics were each issued a Russian-made motorcycle and other clinics received a total of 34 bicycles and one clinic, a donkey. The total cost was \$US 2 504. The United Nations Office for the Coordination of Humanitarian Assistance for Afghanistan (UNOCHA) donated one Russian-made Zil truck to the project. Its petrol engine was replaced by a diesel engine because of a chronic petrol shortage. It proved very useful for shipping voluminous cold boxes containing vaccine to the field clinics. The purchase order of 35 Japanese motorcycles was never received at the project site, as they were held up at the port of Karachi. It is doubtful whether these motorcycles would have lasted very long as no spare parts were available in Mazar-i-Sharif. Much cheaper and sturdier Russian-made motorcycles were available locally at a fraction of the cost of Japanese motorcycles.

In areas where transport facilities were limited, the project's provision of simple means of transport, such as bicycles, enabled veterinary workers to function from their clinics or dispensaries and attend to the needs of local livestock owners.

\subsubsection{Laboratory equipment}

Laboratory equipment was provided to four provincial clinics, enabling them to carry out basic diagnostic work on blood and faecal samples. The microbiology laboratory in Mazar-i-Sharif was in an initial stage of function at the time of writing. Essential equipment, instruments and chemicals were provided to conduct confirmatory tests for the occurrence of infectious diseases in three other provincial laboratories. The total cost for laboratory equipment, reagents and chemicals amounted to \$US 73983.

Many provincial laboratories had been looted or had deteriorated, with no spare parts for equipment, with equipment instructions in Russian which could only be interpreted with difficulty by veterinarians and laboratory technicians, and with chemical reagents which were exhausted or outdated. The project established some basic diagnostic facilities. Trained technicians provided diagnostic services in areas which for many years had been devoid of such essential facilities. 
A total of 16 clinics or dispensaries were fully renovated, but a total of 36 were equipped and issued with instruments and medicines. Much of this may not be apparent when visiting the clinics, as most of the kits are stored at the veterinarians' private residences for security reasons.

Toward the end of the project all vaccine had been distributed. Substantial stocks of unexpired medicines (with a value of \$US 67250 ), clinical instruments, laboratory instruments and chemicals remained at the project office in Mazar-i-Sharif to be made available to the new programme.

\subsection{TRAINING}

In view of the relatively short project duration, BVWs with their training of two weeks suited the needs of the project better than para-veterinarians whose training would have required a period of six months.

Whereas the Project Document targeted the training of 60 vaccinators, during the project period a total of 282 BVWs were trained in basic veterinary skills in selected districts. Of these, 275 could be located in a recent identification exercise. An estimated 70\% (193) were still actively working at the time of writing, and the remainder were only seasonally active or had found alternative employment. It is important to keep track of these BVWs so that in case of a disease outbreak, they can be called upon at short notice to assist in emergency vaccination campaigns.

A total of 54 veterinarians underwent refresher courses provided by the project on modern veterinary clinical diagnosis and treatment. Three veterinarians were trained in basic laboratory methods. Veterinarians and BVWs were equipped with start-up kits upon completion of the courses.

A senior representative of the Veterinary Services Department was awarded a study tour to attend a regional conference organized by the International Office of Epizootics (OIE) in Iran in 1991. Study tours were also awarded to three staff members to attend a short course in project management organized by FAO in Egypt.

Based on an estimated coverage of five villages per BVW living in a village and of 15 villages per BVW or veterinarian located in a district centre, an estimated 2500 villages now have access to basic animal health service in northern Afghanistan. The development of 
human resources well beyond the targets set out in the Project Document is considered to be one of the project's major achievements toward the establishment of a community-based veterinary service in rural Afghanistan.

\subsection{DISEASE CONTROL PROGRAMME}

The disease control programme, which was community based and relied on cost recovery, was implemented mainly through BVWs. Records of disease outbreaks, occurrences of infectious diseases and results of laboratory investigations were compiled. Medicine distribution records, lists of treatments for various ailments, vaccine distribution records and actual vaccination records were kept at the project's office.

Many diseases have a bi-modal seasonal pattern, thereby determining the optimal times to effect vaccinations. Autumn and spring are the technically preferred times to vaccinate livestock in northern Afghanistan with the selection of vaccines provided by the project. These times fit well with the animal husbandry calendar, as livestock are gathered for winter housing and are thus more accessible. Poultry require vaccination against Newcastle disease (and others) throughout the year according to their production cycle. Most vaccinations for poultry take place while they are less than two months old. Follow-up vaccination is best carried out during the winter season, as the cold weather facilitates storage and transport of vaccines from one area to another.

The winter 1993 vaccination campaign was partly forced upon the project because of the imminent expiry date of some vaccines. This resulted from the partial interruption of normal project activities during evacuation from the north. A Food-for-Work project was approved by the World Food Programme (WFP), and 49 tonnes of wheat were distributed as an incentive to the veterinary workers participating in the campaign. In addition to achieving a broad vaccination coverage, the campaign motivated veterinarians and village residents to cooperate in an important endeavour to prevent disease and deaths in livestock. 
Table 2

VACCINATIONS REPORTED (all species combined)

\begin{tabular}{|c|c|}
\hline $\begin{array}{l}\text { July to Dec. } 1991 \\
\text { Jan. to June } 1992 \\
\text { July to Dec. } 1992 \\
\text { Jan. to July } 1993 \\
\text { Sept. to Dec. } 1993 \\
\text { Jan. to Aug. } 1994\end{array}$ & $\begin{array}{r}25510 \\
\text { no vaccine available } \\
40298 \\
1700000 \\
4140393 \\
1538787\end{array}$ \\
\hline Total reported & 7443208 \\
\hline
\end{tabular}

Requests by the Government to include rinderpest (RP) and foot-and-mouth disease (FMD) in the vaccination programme have yet to be implemented on the basis that RP vaccination would be dealt with on an emergency basis during outbreaks of the disease and FMD vaccination was not feasible with the limited cold chain and transportation available. Additionally, control of FMD is generally a public good and is therefore organized and supported by the Government. The effectiveness of vaccinating goats against contagious caprine pleuropneumonia (CCPP) is questionable and the quality of the vaccine needs further investigation.

Diseases of public health importance were identified and highlighted by the project, but under the prevailing circumstances little could be done about such basic concepts as reintroducing meat inspection and the destruction of stray dogs in order to avert the spread of rabies, echinococcosis and other zoonotic diseases. The project assisted one community in the construction of a modest abattoir.

Although vaccination programmes are costly, their continued administration is considered justified, as preventive vaccination is known to be cost-effective. Vaccination campaigns also cement patient-client-veterinarian relationships, which are vital for selfsupporting delivery of community-based veterinary services. Contact with farmers also affords the opportunity for extension and treatment of other aliments (such as parasites, lameness and wounds) which affect production. It is also considered too early to start cost recovery for the vaccines, as it is believed that farmers will not want their animals vaccinated when the disease does not threaten their stock, thus again rendering their flocks susceptible to infection. 


\subsection{LIVESTOCK DATA COLLECTION}

Veterinary workers regularly submit standard data collection forms. Submission of completed forms is conditional to the replenishment of medicines. Clinic and dispensary status information is recorded. A data base was created concerning disease occurrence, medicine utilization, vaccinations and deworming, as well as the results of faecal sampling and blood smears.

Observational studies of the natural occurrence of diseases were initiated in four districts with sentinel flocks of 30 to 50 sheep/goats, each flock containing control animals which were not vaccinated or treated. Blood and faecal samples were analysed and data recorded. Regular monthly monitoring has been difficult to carry out, due to the seasonal migration of flocks and security restrictions for both the flock owners and project staff.

Analysing information in the data base was hampered by the cancellation of the second visit of the epidemiology consultant. Data compiled from field records were carefully counterchecked by project staff to form the basis for analysis by an epidemiology consultant under the new programme.

\subsection{COMMERCIAL SUPPLY OF VETERINARY NEEDS}

Under current conditions, it was possible to interest traders inside Afghanistan to invest in the importation of veterinary supplies at the required scale because of the risks involved. Outside the country, in Pakistan, traders were willing to do business but required guaranteed orders, storage facilities, safe transportation and a stable money market.

As is the case for human medicines, it is possible to import small quantities of veterinary medicines. To import large quantities requires a variety of permits, and large consignments are more subject to looting along the way. It is not advisable to import vaccines through traders because of the lack of quality assurance and the cold chain requirement. The readily accessible supply market has been from Pakistan. While the traditional supply route through Kabul is now closed, the opportunity to import quality medicines from Iran, Commonwealth of Independent States (CIS) countries and China should be investigated.

A component for small business enterprise development should be included in any new programme dealing with the commercialization of veterinary supplies. 


\subsection{FUTURE DEVELOPMENT}

Three months before the project's termination date, a new countrywide Integrated Livestock Programme became operational on 1 July 1994. This programme merges the northern veterinary FAO/UNDP-executed project with the southern veterinary component of the OPS/UNDP-executed programme into one programme under FAO execution. The direct project implementation employed in the northern veterinary project will be substituted by the OPS approach of implementation through subcontracts with NGOs. The merging of two existing veterinary projects into one national programme aims at extending Veterinary Field Units (VFUs) and at delivering community-based animal health services for the whole of Afghanistan. A component was added for rehabilitating selected livestock production activities, particularly those identified during the Afghanistan Rehabilitation Strategy Action Plan. 


\section{RECOMMENDATIONS}

\subsection{LEGALIZING VETERINARY PRIVATE PRACTICE}

There is an urgent need for the future Government to recognize that the veterinary profession has evolved from the institution it once was into a de facto privatized and more effective enterprise committed to delivering services to the rural community. In accepting the benefits resulting from the UNDP-supported projects, the Government could then concentrate its efforts on essential public veterinary services such as meat inspection, disease control and eradication programmes, public health, laboratories for disease investigation and related essential animal health services.

In accepting the concept of self-employed veterinarians, para-veterinarians and BVWs, the Government should legalize this practice and exercise monitoring activities to ensure the delivery of quality services. The latter should be carried out through continuing education, licensing and regulation to ensure the importation of quality-assured remedies and vaccines, disease investigation through provincial laboratories and monitoring to protect consumer interests.

\subsection{ENSURING SUSTAINABILITY}

The main achievement of the project has been to facilitate the privatization of veterinary services delivery by offering assistance to the 54 veterinarians and 202 BVWs to become established as private practitioners and earn an income from the delivery of community-based animal health services. This was achieved without payment of direct salaries as these veterinarians were already established in the project areas. BVWs were trained and deployed and their selection was made with the involvement of the community. Thus no loss of either trained veterinarians or BVWs is anticipated so long as they are kept adequately supplied with medicines and vaccine. The general absence of a privatized supply network for medicine and vaccine may mean the loss of income for veterinary workers and an end to assistance to livestock owners in northern Afghanistan. This gap will be temporarily filled by the Integrated Livestock Programme (project AFG/93/004) which will further develop a reliable supply of remedies by the private sector. 
It is therefore recommended that interim assistance be given to all veterinary workers in the project area, through the sale of medicines and the free issue of vaccine. This assistance could be delivered through an NGO relatively inexpensively, as the cost recovery of medicines is an acquired principle with veterinary workers and livestock owners in northern Afghanistan. Once the supply is guaranteed, veterinarians would report back on such details as disease occurrences and vaccination records, which would be conditional to being resupplied. The new programme must take a flexible approach in addressing the need for veterinary assistance in various areas, even if it runs the risk of having more than one policy. A consultancy would be justified to review the methodology of cost recovery and self-sustainability used as an important precedent by the project and which could have beneficial applications in the new programme.

The follow-up Integrated Livestock Programme will take a uniform approach for the entire country through the continued use of subcontracts with NGOs and/or community organizations. These are to support Veterinary Field Units while paying different grant amounts to the VFUs for services. While it is fair that the veterinarians in the northern project area can now be paid as their colleagues in the south have been for the past five years, this is a costly and probably unnecessary approach where private practices are already established from which veterinarians make an income. What probably should have been done was to eliminate payments to veterinarians in the south altogether instead of introducing payments in the north. This system of salary payments cannot be sustained in the long run and is opposed to the essence of private enterprise. Instead, the key issue which needs to be addressed is the supply of medicines to the veterinary workers.

\subsection{VETERINARY PUBLIC HEALTH}

It is recommended that livestock vaccination remain free of charge for diseases such as anthrax which are communicable to humans, through the continued use of vaccination campaigns. There is an urgent need to obtain additional funding for the initiation of an effective system of meat inspection, for the organization of a rabies control programme through tie-up orders and the destruction of stray dogs, and for measures to control infectious agents in animal by-products (intestines, hides and wool) presently exported without valid laboratory test certificates. 
These activities could be further developed and formulated into a sub-project on veterinary public health. With a well-defined programme, it may be an attractive proposal likely to be supported by donors.

\subsection{PRIVATIZATION OF VETERINARY MEDICINE DISTRIBUTION}

It is recommended that a Contractual Services Agreement (CSA) be made with an NGO specialized in the field of small business enterprise development, with the aim of establishing a network for the distribution of veterinary medicines and supplies. This NGO could be technically backed by consultants from an organization such as the International Labour Organization (ILO). Part of the funds needed for this CSA could be made available from money already recovered from the sale of medicines under the project. 
20 
Appendix 1

PROJECT STAFF

Name

Function

Dates of Service

Starting Date Concluding Date

International

\begin{tabular}{|c|c|c|c|c|c|c|}
\hline P. Leperre & Chief Technical Adviser & 23 June & 1991 & 22 & July & 1993 \\
\hline P. De Roover & Chief Technical Adviser & 27 Sept. & 1993 & 26 & Sept. & 1994 \\
\hline H. Nauheimer & $\begin{array}{l}\text { Consultant (veterinary } \\
\text { epidemiology) }\end{array}$ & 14 Nov. & 1992 & 8 & Dec. & 1992 \\
\hline \multirow[t]{2}{*}{ Khin Maung Win } & $\begin{array}{l}\text { Consultant (disease } \\
\text { investigation) }\end{array}$ & 11 July & 1993 & 30 & June & 1994 \\
\hline & UNV veterinarian & 21 June & 1991 & 20 & June & 1993 \\
\hline L. Maranda & UNV veterinarian & 1 May & 1991 & 2 & July & 1992 \\
\hline A. Badha & UNV veterinarian & 7 May & 1991 & 30 & June & 1994 \\
\hline Myint Thar & $\begin{array}{l}\text { UNV administrative } \\
\text { specialist }\end{array}$ & 15 Dec. & 1992 & 30 & Sept. & 1994 \\
\hline J. Duncombe & UNV veterinarian & 15 April & 1993 & 30 & Sept. & \\
\hline
\end{tabular}

National

S. Shir Shah

M. Dad

A. Osmani

L. Rostaqi

Daoud S. Sayed

A. Tellaiy

A.B. Afif

Ghulam Nabi

A. Afzali

Z. Daftari

M. Osman

A. Fawad Nasred Mir

S. Nooragha

A. Wodood

G. Rasoul

A. Wakil

N. Noorullah
Veterinarian

Veterinarian

Veterinarian

Veterinarian

Administrative clerk

Secretary

Storekeeper

Clerk/storekeeper

Field officer

Clerk/typist

Junior clerk

Senior driver

Driver

Driver

Driver

Driver

Watchman

Watchman
6 May $1993 \quad 30$ June 1994

6 May $1993 \quad 30$ June 1994

1 Oct. 199330 June 1994

1 Oct. 199330 June 1994

15 July $1993 \quad 30$ June 1994

15 July $1993 \quad 14$ July 1994

21 Feb. 199430 June 1994

12 July $1993 \quad 14$ Feb. 1994

23 Feb. 199430 June 1994

1 Oct. $1993 \quad 30$ Sept. 1994

31 Jan. $1994 \quad 30$ June 1994

20 June $1992 \quad 30$ June 1994

12 Dec. 199130 June 1994

13 June $1993 \quad 12$ June 1994

13 June $1993 \quad 14$ June 1994

15 July $1993 \quad 30$ June 1994

9 March 199230 June 1994

27 July $1993 \quad 30$ June 1994 


\section{Appendix 2}

\section{STUDY TOURS}

Participants

A. Salemi

P. Leperre
Study

OIE conference on animal diseases in the region

Finalization of project documents, project appraisal, monitoring and evaluation
Place

Iran

Egypt

Egypt

Egypt
Sept. 1991

11-15 April 1993
Khin Maung Win Project management

Project financial management

18-22 April 1993

Myint Thar

25-29 Aprịl 1993 
Appendix 3

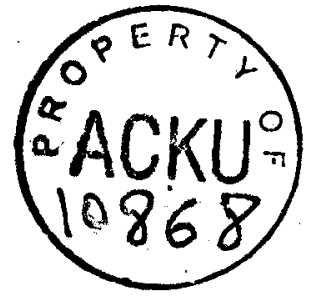

MAJOR ITEMS OF EQUIPMENT PROVIDED

Quantity

$\underline{\text { Item }}$

Cost

(\$US)

\section{A3.1 TRANSPORTATION EQUIPMENT}

$\begin{array}{rlr}6 & \text { Vehicle, Land Cruiser 4-WD, station wagon, Toyota } & 129929 \\ 1 & \text { Vehicle, Hi-Lux 4-WD, double cabin, Toyota } & 18371 \\ 1 & \text { Vehicle, Toyota Corolla model AE92L } & 5000 \\ 35 & \text { Motorcycle, Suzuki model TF 125X, 125 cc } & 43468\end{array}$

\section{A3.2 RADIO COMMUNICATIONS EQUIPMENT}

1 Transceiver 8528, front control $12 \mathrm{~V}$

3649

4 Transceiver 8528, extended control

16314

9 Transceiver, Yaesu, hand-held

4222

1 Transceiver, base station, $12 \mathrm{~V}$, complete

3649

1 Transceiver, mobile unit

2 Transceiver, SSB, $12 \mathrm{~V}$, complete

4083

2 Transceiver, $12 \mathrm{~V}$, extended control

7595

1 Transceiver, front control, SSB, complete

8922

2 Transceiver, Yaesu FTL-2001 VHF, complete

4056

1 Transceiver, front control, HF SSB, 8528, SITOR

1259

5525

\section{A3.3 OFFICE EQUIPMENT}

1 Computer set, lap-top, Toshiba 1200XE/20

4475

1 Computer, Taiwan model 386S Sager

4650

1 Computer, Toshiba T3300SL, with printer

3797

1 Computer, notebook Toshiba T-3300 SL

4303

1 Computer, Toshiba laptop model 1200

778

1 Printer, Epson model LQ-2550

1 Printer, Epson model LQ-500

1963

1 Printer, Canon Bubble Jet model BJ-10SX

809

4 Typewriter, portable, manual, Olivetti

1 Typewriter, electric, Adler

271

1 Typewriter, Persian 18"

2 Calculator, Casio model dc-850

1 Photocopier, desktop zoom, Canon NP-1215

1 Photocopier, Canon FC-2

Photocopier, Canon FC-2

2 Voltage regulator, automatic, Stavol SVC-300N, $3 \mathrm{kVA}$ 
Quantity

$\underline{\text { Item }}$

Cost

(\$US)

\section{A3.4 COLD CHAIN EQUIPMENT}

1 Air conditioner, General AGG-24H, 23700 BTU 1492

1 Air conditioner, General AGG-18H, 18000 BTU, floor-type 1238

1 Generator, Yanmar model TPM-1000

8500

2 Generator, Kubota model AE-3500, $3 \mathrm{~kW}$

1275

1 Generator, Suzuki model SE-700, $1 \mathrm{~kW}$

500

1 Generator, Kubota model GV-3150, diesel

7098

2 Generator, Kubota model ASKR-3100

8989

1 Generator, Kubota model ASKR-150B, $5 \mathrm{~kW}$

2943

2 Solar power refrigerator kit, including module

6964

2 Solar power packs, transportable

6247

2 Refrigerator, stationary Camel system

11969

Refrigerator, mobile

2856

40 Cold box, Electrolux, plus ice packs

23354

5 Refrigerator, Russian

6 Air conditioner, Russian

1257

927

\section{A3.5 LABORATORY EQUIPMENT}

1 Incubator, $115 \mathrm{MM}$

1680

2 Microscope model G60, eyepiece WFx10

1206

1 Microscope, student and laboratory

1951

1 Sterilizer, high pressure, horizontal

2303

1 Weigh scale, electronic, balance top loading

2101

\section{A3.6 VETERINARY EQUIPMENT}

Medicines

213131

Vaccines

514000

Instruments

92612

\section{A3.7 TEACHING AIDS}

1 Overhead projector, portable, A\&K 300 
Appendix 4

DOCUMENTS PREPARED DURING THE PROJECT

Inception report. P. Leperre, Aug. 1991.

Six-monthly progress report: July-Dec. 1991. P. Leperre, 1991.

Six-monthly progress report: Jan.-June 1992. P. Leperre, 1992.

Project performance evaluation report. P. Leperre, June 1992.

Veterinary epidemiology consultancy report. H. Nauheimer, Dec. 1992.

Six-monthly progress report: July-Dec. 1992. P. Leperre, 1992.

Six-monthly progress report: Jan.-June 1993. P. Leperre, 1993.

Inception report. P. De Roover, 1993.

Six-monthly report: July-Dec. 1993. P. De Roover, 1993.

Disease investigation consultancy report. Khin Maung Win, 1993.

Six-monthly progress report of United Nations Volunteers: July-Dec. 1993. A. Badha and J. Duncombe, 1993.

Progress report of national professional project personnel: May-Dec. 1993. M. Dad and S. Shah, 1993.

Progress report of national professional project personnel: Oct.-Dec. 1993. A. Osmani and L. Rostagi, 1993.

Field activity report: Jan.-May 1994. A. Osmani, 1994.

End assignment report: July 1993-June 1994. Khin Maung Win, 1994.

Project review. J. Baker, April 1994.

Project Document for UNDP project AFG/93/004. Cossins and Baker, April 1994.

Training guide for veterinary vaccinators. (In English and Dari.) 
Guidelines for veterinary workers. (Third revision.) April 1993.

Training manual for basic veterinary workers. (In English.) M. Dad and S. Shah.

Project Document for UNOCHA project UNO/AFG/023/UNA. P. De Roover.

End of assignment report: Sept. 1993-Sept. 1994. P. De Roover, 1994. 


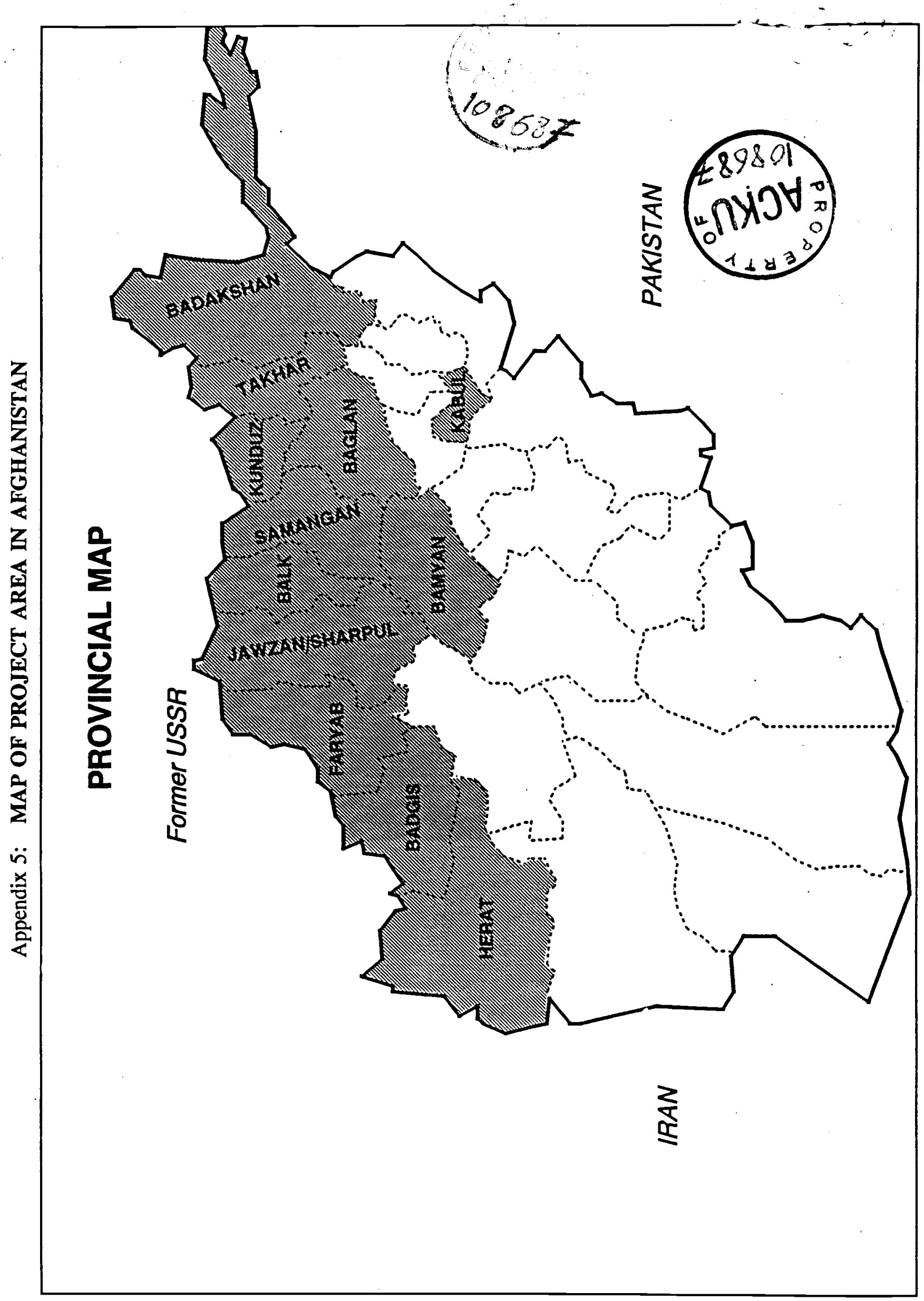

